\title{
The Gordon Scott Topical Collection: articles on peste des petits ruminants and other infectious diseases of domestic livestock
}

\author{
Paul Rossiter • Leslie J. S. Harrison
}

Published online: 14 November 2014

(C) Springer Science+Business Media Dordrecht 2014

Gordon Ramsey Scott is irrevocably linked with the control and eradication of rinderpest. From 1950 to 1962, his research, initially at Kabete and then Muguga laboratories in Kenya, contributed significantly to improved diagnosis and control of rinderpest. Returning to Scotland and the post of lecturer in tropical veterinary medicine at the Royal "Dick" Veterinary School and the subsequent Centre for Tropical Veterinary Medicine (CTVM), Gordon's enthusiasm for teaching infectious diseases and their control made him a popular figure with hundreds of students who attended courses there. At the CTVM, he played an important role in the start and ensuing success of the Centre's own journal, Tropical Animal Health and Production, both as consultant scientific editor and contributor and in his eventual position of "Reader Emeritus" maintained his involvement with the journal during his retirement. His knowledge of rinderpest was frequently sought by international agencies such as the Food and Agriculture Organization of the United Nations, and in 1992 he and Dr Alain Provost produced the background document for the establishment of the Global Rinderpest Eradication Programme (Scott and Provost 1992). During the 1970s and 1980s, he became involved with peste des petits ruminants (PPR) in West Africa and the process of showing that the different syndromes known as PPR, "kata" and pneumo-enteritis were one disease, and in promoting its

This article belongs to the Topical Collection: The Gordon Scott Collection - articles on PPR and other infectious diseases of tropical livestock Guest Editor: Paul Rossiter

P. Rossiter $(\bowtie)$

St Michael's House, Poughill, Devon EX17 4LA, UK

e-mail: paulrossiter@btinternet.com

L. J. S. Harrison

University of Edinburgh, Easter Bush Veterinary Centre, Roslin, Midlothian EH25 9RG, UK similarities with rinderpest and the concept that it was equally susceptible to eradication (Scott 1981). Since Gordon's death in 2004, rinderpest has been globally eradicated and now, a decade later, PPR has been officially identified as the next livestock disease to be specifically targeted for global control leading to possible eradication (OIE 2014).

In keeping with new trends in the publication of scientific research, Tropical Animal Health and Production (TAH\&P) is launching a topical collection of papers on PPR and other infectious diseases predominantly affecting tropical livestock. To commemorate his close association with rinderpest and PPR, and with this journal, this collection will be known as "The Gordon Scott Topical Collection" (GSTC). Articles accepted for the GSTC will be published in Tropical Animal Health and Production in routine fashion but form part of a specific collection of papers that can be accessed as a whole. It is anticipated that the GSTC will become the site for an increasing number of quality papers on PPR in particular as well as some other infections and, over time, prove a valuable record of the development of new ideas and methodologies leading to the eradication of PPR and possibly other diseases. The types of contributions to be considered include commentaries and reviews on selected topics affecting the control of PPR, as well as laboratory and field research findings and periodic summaries of progress towards global control. The editors will invite occasional contributions from known authorities in these fields. The common factor in all articles on PPR will be their relevance to improved control and the beneficial impact this should have on livestock owners. The GSTC will have no time frame and hopes to attract longerterm studies of the disease and its control in the field. Significant investigations of the epidemiology of PPR are very relevant though short-term studies including brief serosurveys or the genotyping of virus isolates will be considered where they relate to known episodes of disease and vaccination, and the practical aspects of control. Emphasis must 
always be placed upon linking laboratory results to the field, especially to clinical and epidemiological findings. Submissions from field staff working in the front lines of control will be very welcome especially where these report successful initiatives though unsuccessful ones may also be considered where there are clear lessons to be shared. Comprehensive studies of the negative social-economic impact and true costs of PPR in communities are needed to support the justification for global eradication. Among the other diseases to be considered are those with serious, negative impact on the livelihoods of poor livestock owners in the countries traditionally associated with $T A H \& P$; these include sheep and goat pox, rift valley fever, contagious caprine pleuropneumonia and brucellosis of small ruminants. Studies in cattle and other domestic livestock including camels will be considered especially if dealing with infection with PPR virus, as well as diseases such as lumpy skin disease and malignant catarrhal fever, both of which Gordon contributed to. Retrospective reports and studies on rinderpest prior to global eradication may be reviewed where these provide lessons bearing directly on improved control of PPR and other diseases.
Authors who wish to contribute a paper to the GSTC should indicate this on their submission with the understanding, however, that it may not be accepted for "The Collection" even though accepted for general publication in TAH\&P. The editors have invited another Edinburgh graduate, Dr William Taylor, to launch the GSTC with a contribution on PPR. Dr Taylor is widely known for his work on rinderpest and pioneering studies of PPR including the isolation in Nigeria of the strain of the virus that has become the most widely used attenuated vaccine today.

\section{References}

Office International des Epizooties. 2014. Final report of the 82nd General Session, May 2014: resolution 24, pp 164-166., OIE, Paris.

Scott, G.R (1981). Rinderpest and peste des petits ruminants: in Gibbs, P. Virus diseases of food animals. A world geography of epidemiology and control. Disease Monographs, vol II, 401-432. Academic Press, London.

Scott, G.R. and Provost, A. 1992. Global eradication of rinderpest. FAO Expert Consultation on the Strategy for Global Rinderpest Eradication, Rome, October 1992. FAO, Rome. 